Indian J Anim Health (2021), 60(2): 292-294

DOI: https://doi.org/10.36062/ijah.2021.09921

Short Communication

\title{
Obstetrical management of post cervical left-sided uterine torsion in a Hariana cow: A case study
}

\author{
L. Kipjen Singh ${ }^{1 *}$, U. Singh ${ }^{1}$, C. R. Chaudhary ${ }^{2}$ and P. Singh ${ }^{2}$
}

${ }^{1}$ Department of Veterinary Gynaecology and Obstetrics, International Institute of Veterinary Education and Research, Rohtak, Haryana-124 001, India; ${ }^{2}$ Department of Veterinary Clinical Complex, International Institute of Veterinary Education and Research, Rohtak, Haryana-124 001, India

\begin{abstract}
Uterine torsion is one of the most common gestational disorders of bovine. A six-year-old Hariana cow in its fourth parity at a completed gestation was presented at the Veterinary Clinical Complex with a history of labour straining and abdominal discomfort for last 30 hrs without any progression of calving. Per vaginal examination revealed post cervical left side uterine torsion with more than $180^{\circ}$ rotations. The animal was anaesthetized with $0.5 \mathrm{~mL}$ xylazine intravenously and placed on left lateral recumbency. Detorsion was done using modified Schaffer's method of rolling by the help of a plank with three continuous rollings. Torsion was relieved and per vaginal examination revealed three fingers dilation of os-cervix (incomplete cervical dilation). Dilation therapy was done and after $2 \mathrm{hrs}$, the cervix was fully dilated. Mild traction was applied and a dead fetus was delivered successfully. The animal recovered uneventfully.
\end{abstract}

Key words: Dystocia, Hariana cow, Modified Schaffer's method, Uterine torsion

\section{Highlights}

- Uterine torsion is treated as an emergency gestational disorder

- Liver and kidney function test of the buffaloes can be used as a prognostic indicators for the future outcome of uterine torsion affected buffaloes

- Timely diagnosis and early correction of uterine torsion will save the life of the dam and fetus

Uterine torsion leading to dystocia (difficulty birth) is reported to be more common in bovines (Erteld et al., 2012). It is defined as the rotation of the pregnant uterus on its longitudinal axis (Purohit et al., 2011). Uterine torsion is considered as an obstetrical emergency as it can cause the death of both dam and fetus if not treated early. It is mainly seen in pluriparous than primiparous animals and is usually occurred in the late $1^{\text {st }}$ stage and early second stage of parturition (Jeengar et al., 2015). The exact cause of uterine torsion is still unknown however, there are some speculations. The direction of torsion can be either clockwise (right-sided) or in anticlockwise (left-sided) direction. Torsion may be post cervical (caudal to the cervix and involves rotation of anterior vagina) and pre cervical uterine torsion (cranial to the cervix and involves uterine body rotation), in which post cervical uterine torsion is more common in bovines (Noakes et al., 2009). The degree of torsion can be varied between $45^{\circ}$ to $360^{\circ}$ (Jeengar et al., 2015). The diagnosis of uterine torsion was based on per vaginal and per rectal examination, in which per rectal examination is considered to be best for pre cervical torsion (Noakes et al., 2009). The successful management of uterine torsion lies in correct and efficient diagnosis (Purohit et al., 2011). Thus, the paper describes the successful obstetrical management of post cervical left-sided uterine torsion followed by incomplete cervical dilation in a Hariana cow.

A six-year-old Hariana cow in its third parity at a completed gestation is presented at the Veterinary Clinical Complex of International Institute of Veterinary Education and Research,

\footnotetext{
"Corresponding Author, E mail: laishramkipjen04@gmail.com
} 


\section{Obstetrical correction of uterine torsion in a Hariana cow}

Rohtak, Haryana with a history of labour straining and abdominal discomfort since $30 \mathrm{hrs}$ without any progression of calving. On physical observation and clinical examination, the cow showed abdominal pain, kicking of abdomen, alert, active and restlessness. The rectal temperature is recorded as $101.4^{\circ} \mathrm{F}$. Per vaginal examination revealed twisting of vaginal folds and fingers to the left side direction (anticlockwise). The case was diagnosed as post cervical left-sided torsion with more than $180^{\circ}$.

The animal is anaesthetized with intravenous injection of xylazine @ $0.1 \mathrm{mg} / \mathrm{kg}$ b. wt. and cast on the left lateral recumbency as the direction of torsion with both forelimbs and hind limbs secured with rope separately (Fig. 1). Correction of torsion is done using modified Schaffer's method of rolling with a plank. Briefly, a wooden plank of 3-4 m long, $20-30 \mathrm{~cm}$ wide is placed on the paralumbar fossa of a dam in an inclined manner with a lower end on the ground according to modified Schaffer's method and rolling was done as the direction of torsion. The vaginal examination is done in each rolling and detorsion was achieved with three rollings indicating threefinger dilation of os cervix. The dilation of the cervix was initiated with the injections of valethamate bromide $40 \mathrm{mg}$, dexamethasone sodium $40 \mathrm{mg}$ and cloprostenol sodium 500 $\mu \mathrm{g}$ intramuscularly (Sagar et al., 2021). The cervix was fully dilated and the appearance of a water bag after 2 hrs of dilation therapy (Fig. 2 ). The animal was further restrained in a standing position and 2\% lignocaine @ 0.22 $\mathrm{mg} / \mathrm{kg}$ b.wt. was given epidurally to avoid the pain and straining. Per-vaginal examination revealed the fetus in normal presentation, position and posture. Mild traction was applied and a dead fetus was delivered (Fig. 3). The placenta was expelled after 10 mins delivery (Fig. 4). Post-delivery, six Furex boli were deposited intrauterine and the animal was administered with the injections of enrofloxacin @ $7.5 \mathrm{mg} / \mathrm{kg}$ b.wt., meloxicam @ $0.5 \mathrm{mg} / \mathrm{kg}$ b.wt. and chlorpheniramine maleate @ $0.4 \mathrm{mg} /$ kg b.wt. intramuscularly and liquid Involon@ $100 \mathrm{~mL}$ orally for three consecutive days. The animal was recovered uneventfully and discharged on the same day after treatment.

The present case depicted maternal dystocia due to uterine torsion followed by incomplete cervical dilation in a Hariana cow. Post cervical left-sided uterine torsion observed in the case is rarely occurred as compared to right-sided uterine torsion (Alfaris et al., 2014). The cause of post cervical left-sided uterine torsion in the present case may be due to unfilled rumen leading to an increase in abdominal space and relatively unstable pregnant uterus, which is also reported by Drost (2007). The observed degree of torsion is more than $180^{\circ}$ and left-sided which is constant with other reports (Noakes et al., 2009). The correction of post cervical left-sided uterine torsion was done by modified Schaffer's method of rolling. Detorsion of uterine horn accompanied by incomplete cervical dilation was noticed in the case and the dilation therapy was also done for incomplete cervical dilation. Similarly, Jeengar et al. (2015) reported that detorsion is often accompanied with closed or insufficient dilated $(48 \%)$ than dilated or open cervix $(32 \%)$ which were altered after drug therapy into the opened (64\%) and in the dilated cervix $(16 \%)$. Previous reports showed that the increase in the degree of torsion (twisting of the pregnant uterus) leads to compression of the middle uterine artery and decreased in oxygen supply to the fetus (Schonfelder et al., 2005) which was the sole responsible for fetal death, was also observed in the case. Thus, diagnosis and obstetrical management of uterine torsion should be done as early as possible and modified Schaffer's method of rolling can be attempted followed by induction therapy in post cervical left-sided uterine torsion in Hariana cow.

Conflict of interest: Authors have no conflict of interest in this study.

Author's contribution: LKS: Performed the clinical case, conceptualized, designed, prepared and revised the manuscript; US: Conceptualized and designed the article; CRC: Performed the clinical case; PS: Helped in designing the article. 
Indian Journal of Animal Health, December, 2021

Obstetrical correction of uterine torsion in a Hariana cow

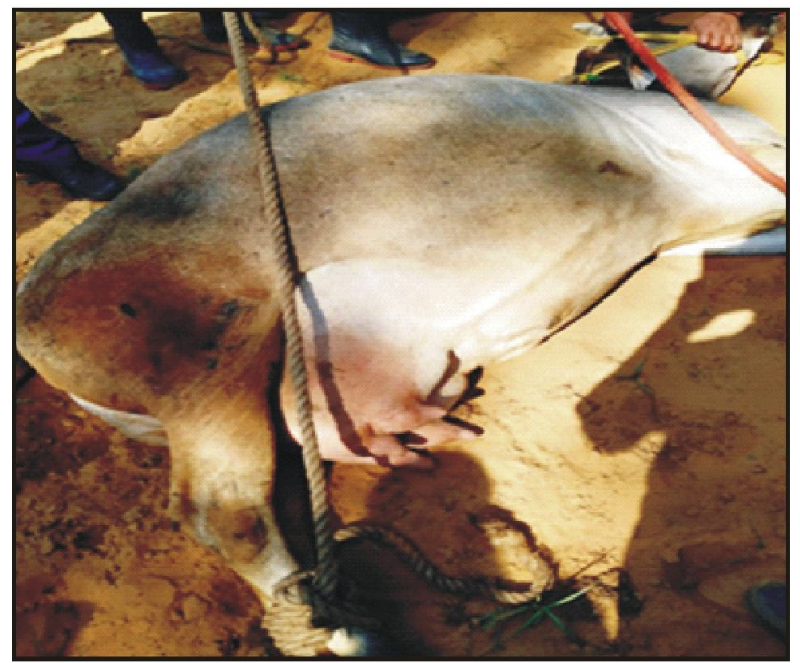

Fig. 1. Animal cast on left lateral recumbency

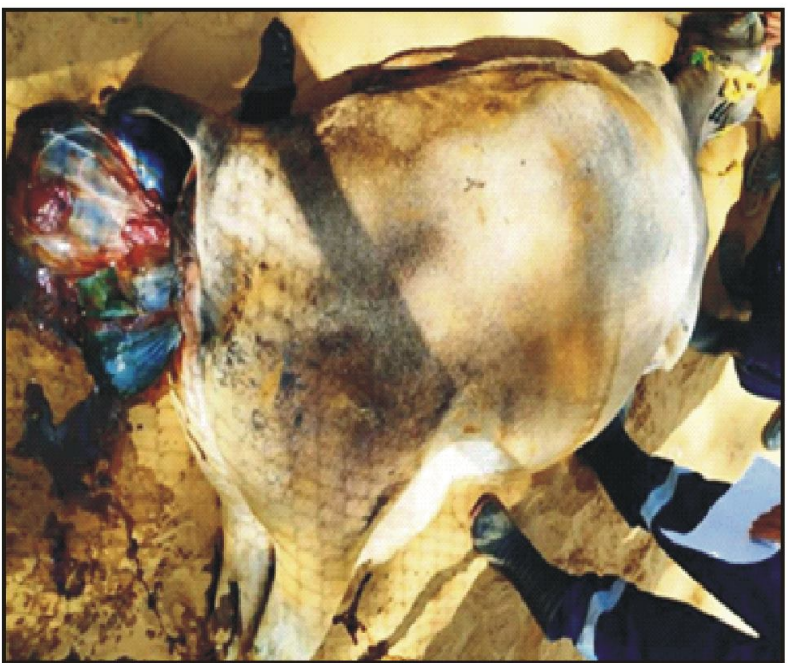

Fig. 2. The appearance of water bag after detorsion
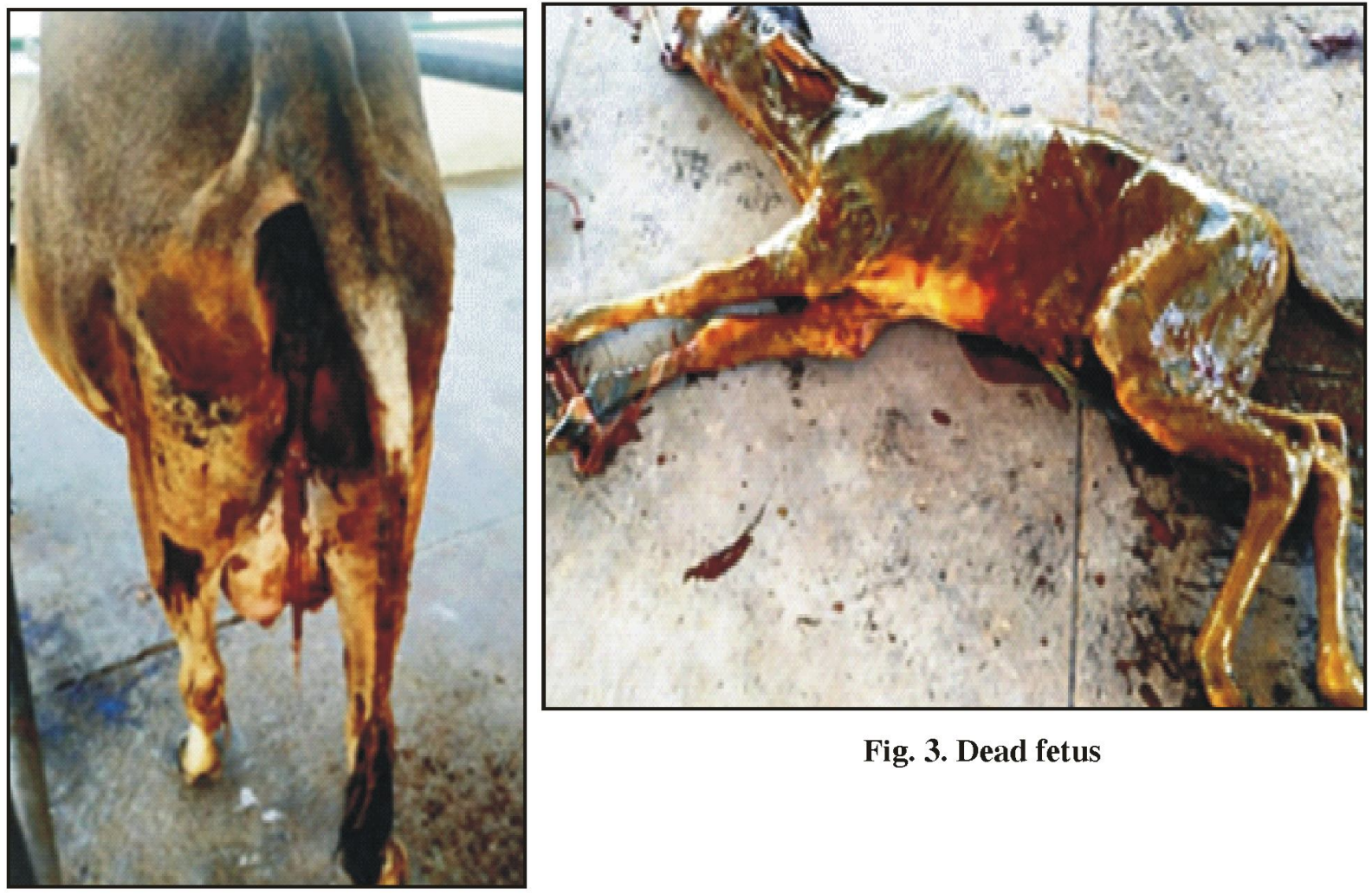

Fig. 3. Dead fetus

Fig. 4. Appearance of placenta 


\section{ACKNOWLEDGEMENT}

The authors are highly thankful to the Chairman and Dean, International Institute of Veterinary Education and Research, Rohtak,

\section{REFERENCES}

Alfaris AA, Fahad TA and Hassan BJ, 2014. Comparison between rolling and surgical treatment of uterine torsion in buffaloes (Bubalus bubalis) in Basrah province. J Vet Med Anim Health, 6(2): 67-68, doi: $10.5897 /$ JVMAH2013.0238

Drost M, 2007. Complications during gestation in the cow. Theriogenology, 68(3): 487-491, doi: 10.1016/j.theriogenology.2007.04.023

Erteld E, Wehrend A and Goericke-Pesch, S. 2012. Uterine torsion in cattle-frequency, clinical symptoms and theories about the pathogenesis. Tierarztliche Praxis. Ausgabe G, Grosstiere/ Nutztiere, 40(3): 167-175, doi: 10.1055/s-00381623110

Jeengar K, Chaudhary V, Maharia SV and Purohit GN, 2015. A retrospective study on type and extent of uterine torsion in buffaloes. Res J Vet Pract, 3(1):
Haryana for providing necessary facilities in the Veterinary Clinical Complex for the treatment of animals.

25-28, doi: 10.14737/journal.rjvp/2015/3.1.25.28 Noakes DE, Parkinson DJ and England GCW, 2009. Maternal dystocias. Arthurs Veterinary Reproduction and Obstetrics, (9 $9^{\text {th }}$ Edn.) W.B. Saunders Company Ltd. London

Purohit GN, Barolia Y, Shekher C and Kumar P, 2011. Diagnosis and correction of uterine torsion in cattle and buffaloes. Raksha Techn Rev, 1(1): 11-17

Sagar R, Saxena S, Kumar S and Kumar S, 2021. Clinical study of incomplete cervical dilation in dairy cattle and buffaloes. Ind J Vet Sci Biotech, 17(2): 102-104

Schonfelder A, Richter A and Sobiraj A, 2005. Doppler ultrasound studies of the uterine arteries in cows with spontaneous parturition and with uterine torsion intrapartum. Wien Tierarztl Monat, 92(3): $74-80$ 